\title{
Soil Health Assessment of Two Regenerative Farming Practices on Sandy Soils
}

\author{
Nan Xu ${ }^{1}$, Jehangir H. Bhadha ${ }^{1}$, Abul Rabbany ${ }^{2} \&$ Stewart Swanson $^{3}$ \\ ${ }^{1}$ Soil and Water Sciences Department, University of Florida, Belle Glade, Florida, USA \\ ${ }^{2}$ Everglades Research and Education Center, University of Florida, Chemist III., Belle Glade, Florida, USA \\ ${ }^{3}$ IFAS Extension, University of Florida, Extension Agent III., LaBelle, Florida, USA \\ Correspondence: Jehangir H. Bhadha, Everglades Research and Education Center, University of Florida, \\ Chemist III., Belle Glade, Florida, USA. E-mail: jango@ufl.edu
}

$\begin{aligned} & \text { Received: September 19, } 2019 \\ & \text { Accepted: October 15, } 2019 \text { Online Published: October 19, } 2019 \\ & \text { doi:10.5539/sar.v8n4p61 }\end{aligned}$ URL: https://doi.org/10.5539/sar.v8n4p61

\begin{abstract}
The addition of organic amendments and cover cropping on sandy soils are regenerative farming practices that can potentially enhance soil health. South Florida mineral soils present low soil quality due to their sandy texture and low organic matter $(\mathrm{OM})$ content. Few studies have focused on evaluating the effects of farm-based management regenerative practices in this region. The objective of this study was to evaluate changes in soil properties associated with two regenerative farming practices - horse bedding application in combination with cover cropping (cowpea, Vigna unguiculata), compared to the practice of cover cropping only for two years. The soil quality indicators that were tested included soil $\mathrm{pH}$, bulk density, water holding capacity, cation exchange capacity, OM, active carbon, soil protein and major nutrients (N, P, K). Results indicated no significant changes in soil $\mathrm{pH}$, but a significant reduction in soil bulk density and a significant increase in maximum water holding capacity for both practices. Cation exchange capacity and the amounts of active carbon increased significantly after 1.5-year of the farming practices. Horse bedding application with cover cropping showed a significant $4 \%$ increase in OM during a short period. A significant increase in plant-available $\mathrm{P}$ was also observed under these two practices. Based on this study, horse bedding application as an organic amendment in conjunction with cover cropping provides an enhanced soil health effect compared to just cover cropping. As local growers explore farming option to improve soil health particularly during the fallow period using regenerative farming practices on sandy soils, these results will assist in their decision making.
\end{abstract}

Keywords: cover cropping, horse bedding, regenerative farming, sandy soils, soil health

\section{Introduction}

Regenerative farming is an approach of farming that focuses on improving and revitalizing soil health. Enhanced soil health is the basis for soil to function sustainably, and to satisfy the needs of humans, support plants and animals, and maintain environmental quality. Regenerative farming aims at promoting productivity and environmental management simultaneously (Pretty, 1995). There is strong evidence that regenerative farming technologies and practices can bring both environmental and economic benefits to farmers, communities, and nations (Sherwood \& Uphoff, 2000). For example, Leontino Balbo's Native Farm in Brazil reported a 20\% increase in sugarcane yield due to zero budget natural farming (ZBNF); integrated duck-rice model conducted in Takao Furuno's farm in Japan reported a 20-50\% rice yield increase as well as a tripling in revenue; and a farmer named Rodney Rulon spent about $\$ 100,000$ on cover crop seeds on his farm in Indiana, but saved about $\$ 57,000$ on fertilizers and $\$ 107,000$ in extra income because of greater yields (Nick, 2019). All of these regenerative approaches focus on soil health management, in an attempt to obtain a balanced relationship between the chemical, biological and physical aspects of a soil, which enhance soil fertility for increasingly productive and sustainable agriculture. The resulting healthy, balanced and mineral-rich soil, not only produces high quality nutritional food and higher crop yields, but also helps carbon sequestration. Conventional agricultural practices can lead to increased greenhouse gas emissions, while regenerative farming promotes an increase in soil organic carbon levels, which helps agriculture to serve as a carbon sink.

Regenerative farming involves sustainable land management practices such as conservation tillage, enhanced 
crop rotations, residue retention, cover cropping, and planned grazing (Rodale Institute, 2014). These farming practices focus on maximizing soil cover and maintaining active roots growing to support soil microbes, which promote an increase in soil organic matter (OM) content, provide benefits of increased productivity and greater resilience on farms, and contribute to soil health and carbon sequestration (Paul, 2013). The improved level of soil OM will result in a greater water-holding capacity and cation exchange capacity, lower soil bulk density, more effective nutrients cycling, increased microbial communities and activities, and improved farm profitability (Rodale Institute, 2014).

\subsection{Objective}

Despite the numerous benefits of regenerative farming practices observed, few studies have focused on evaluating the effects of farm-based management operations, especially in hot and humid southern regions of the United States. Thus, the objective of this study was to evaluate changes in soil health indicators associated with horse bedding application in combination with cover cropping (HB_CC) using cowpea (Vigna unguiculata) in South Florida, and compared to the practice of cover cropping only (CC_only) over a two year period (from January 2017 to January 2019).

\section{Material and Methods}

\subsection{Study Area}

Parts of South Florida are comprised of sandy (mineral) soils, which are left over from the erosion of limestone and deposited from the shallow ancient sea. These mineral soils have developed under a sub-tropical climate with high average temperature and abundant rainfall that promoted microbial growth in soils and rapid OM mineralization over thousands of years. Typically, these mineral soils are of poor quality due to their sandy texture and low soil OM content, which ranges from 1 to $4 \%$ (Bhadha, Capasso, Khatiwada, Swanson, \& LaBorde, 2017). Farming constraints are linked to the natural properties of these mineral soils with a wide range of limiting factors, such as, nutrient deficiencies, poor physical attributes and low water storage capacity (Bhadha, Capasso, Khatiwada, Swanson, \& LaBorde, 2017). Conventional crop production systems on these mineral soils in South Florida rely on large amounts of external nutrients, which also have the potential to be lost via leaching. With these concerns in mind, regenerative farming practices are being developed and evaluated to improve the fertility of these mineral soils and decrease potential impacts on the environment. The use of soil amendments such as horse bedding associated with cover cropping is a management practice that offer alternatives for regenerative cropping production systems by reducing nitrogen fertilizer applications, enhance soil properties, while increasing crop yields. Horse bedding and cover crops could potentially be a good combination in providing nutrients, sequestering carbon, and increasing soil tilth. The practice combines nutrients recovery and protecting the environment, which fits the goal of regenerative farming very well.

\subsection{Horse Bedding Material and Study Plan}

Horse bedding was obtained from local equestrian facilities in Palm Beach County of Florida, which produces over 200,000 tons of bedding material annually. Several basic physiochemical properties of horse bedding material were analyzed in the Soil, Water and Nutrient Management laboratory at the Everglades Research and Education Center in Belle Glade, Florida. A combustion method was used to determine total carbon (C) and total nitrogen $(\mathrm{N})$ percentage of the horse bedding material and calculate its $\mathrm{C}$ : $\mathrm{N}$ ratio. Table 1 shows the basic physiochemical properties of horse bedding.

Table 1. Basic physiochemical properties of horse bedding $(n=3)$

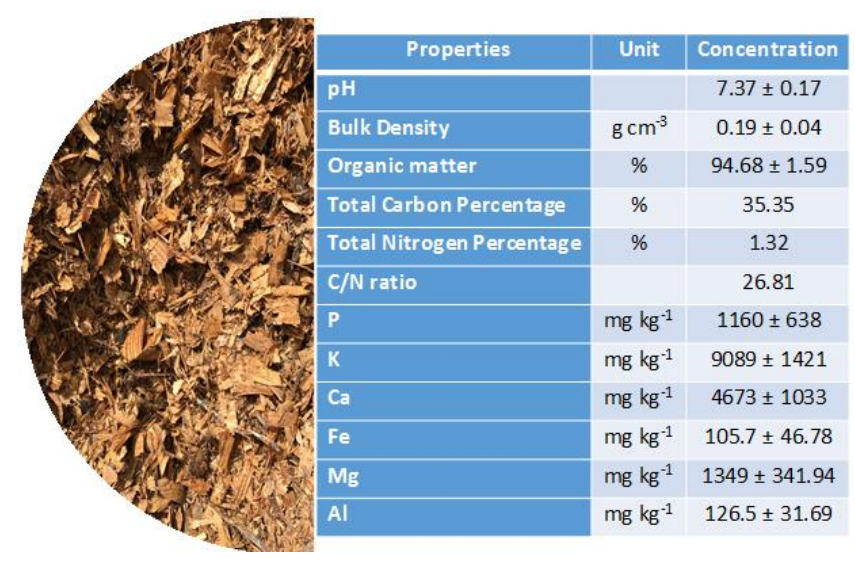


Six 5-acre commercial farm fields in Clewiston, Florida were selected for the management practices. Horse bedding was applied at a depth of 6 inches to three of the fields while the other three went untreated. Three months after the application of horse bedding, Vigna unguiculata was planted at approximately $30 \mathrm{lb} / \mathrm{ac}$ rate and grown during the summer of 2017 in all six fields. The timeline of the management practices is shown in Figure 1.

\section{Horse bedding + Cover crop (HB_CC)}

\section{Cover crop only (CC_only)}
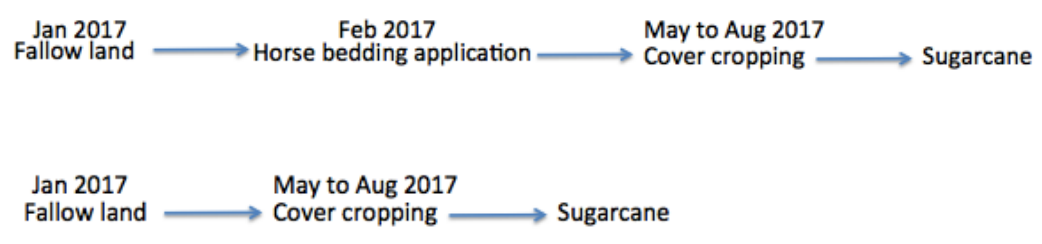

Figure 1. Study timeline of the two regenerative farming practices, (i) Horse bedding + cover crop; (ii) Cover crop only

Baseline soil samples were collected from all six fields in January 2017 prior to horse bedding application into the fields. Second soil sampling was conducted in September 2017, after the cover crop was cut and tilled into the soil, just before sugarcane was planted. A third set of soil samples were collected in January 2019, after the sugarcane was harvested. Five composite soil samples were collected from the top $15 \mathrm{~cm}$ from each field. One composite soil sample comprised of mixing ten soil samples collected along a transect from individual field. All soil samples were collected using 1-gallon Ziploc bags and transported to the Soil, Water and Nutrient Management Laboratory at Everglades Research and Education Center in Belle Glade, Florida for further analyses.

\subsection{Analytical Methods}

All soil samples were air-dried, passed through $2 \mathrm{~mm}$ sieve, and analyzed for soil health indicators, including soil $\mathrm{pH}$, bulk density (BD), maximum water holding capacity (MWHC), organic matter (OM) content, cation exchange capacity (CEC), active carbon (Active C), soil protein, Mehlich 3 phosphorus (M3P) and potassium (M3K), total phosphorus (TP) and total Kjeldahl nitrogen (TKN). Soil pH was determined with a 1:2 soil to water ratio using Accumet AB250 pH meter. Bulk density was calculated by dividing soil mass in a fixed core volume. Maximum water holding capacity was determined by the saturation procedure, which is a modified method described in Jenkinson and Powlson (1976). Organic matter content was calculated through soil material loss on ignition (LOI). Cation exchange capacity was estimated using the ammonium acetate method (Sumner \& Miller, 1996), and ammonium concentration was analyzed with flow injection analysis on a Lachat analyzer (QuikChem Method 10-107-06-2-A. Hach Company, Loveland, CO). Active C was determined based on potassium permanganate $\left(\mathrm{KMnO}_{4}\right)$ oxidizable carbon using $0.02 \mathrm{M} \mathrm{KMnO}_{4}$ for mineral soils, in which approximately $2.5 \mathrm{~g}$ of soil was reacted with $20 \mathrm{~mL}$ of $0.02 \mathrm{M} \mathrm{KMnO}_{4}$ for exactly two minutes, filtered and supernatant solution was then analyzed using Thermo Scientific Genesys 30 spectrophotometer at $550 \mathrm{~nm}$. Soil protein was determined by using a sodium citrate extraction method (Schindelbeck, B.N. Moebius-Clune, D.J. Moebius-Clune, Kurtz, \& van Es, 2016) under autoclaving with high temperature and pressure. The extracted proteins were quantified by using the Thermo Pierce colorimetric bicinchoninic acid assay (BCA) as calibrated against protein standards of known concentration. The color development was read by using Thermo Scientific Genesys 30 spectrophotometer at $550 \mathrm{~nm}$. Plant available P and K were determined using Mehlich-3 extraction method, and then analyzed using Agilent 5110 inductively coupled plasma-optical emission spectrometer (ICP-OES) (Santa Clara CA). Total P was determined by ashing samples for at least 5 hours (not to exceed 16 hours) at $550^{\circ} \mathrm{C}$ in a muffle furnace followed by extraction with $6 \mathrm{M} \mathrm{HCl}$ and analyzed using ICP-OES. TKN was determined using digestion method followed by colorimetric determination (EPA method 351.2).

Analyses of variance for soil properties analyses were performed using a mixed model with treatment (horse bedding application) as the fixed main effects and blocks (plots) were considered as random effects. Statistical analyses were conducted using SAS/GLIMMIX in SAS 9.4 (SAS Institute, 2011). Least significant mean differences $(\mathrm{p}<0.05)$ were determined for significant treatment effects. 


\section{Results}

\subsection{Changes in Soil Health Indicators}

The mean value of $\mathrm{pH}$ for all soil samples were neutral to slightly alkaline and ranged from 6.71 to 7.50 . There were no significant changes in $\mathrm{pH}$ between the two farming practices among the three sampling dates (Figure 2).

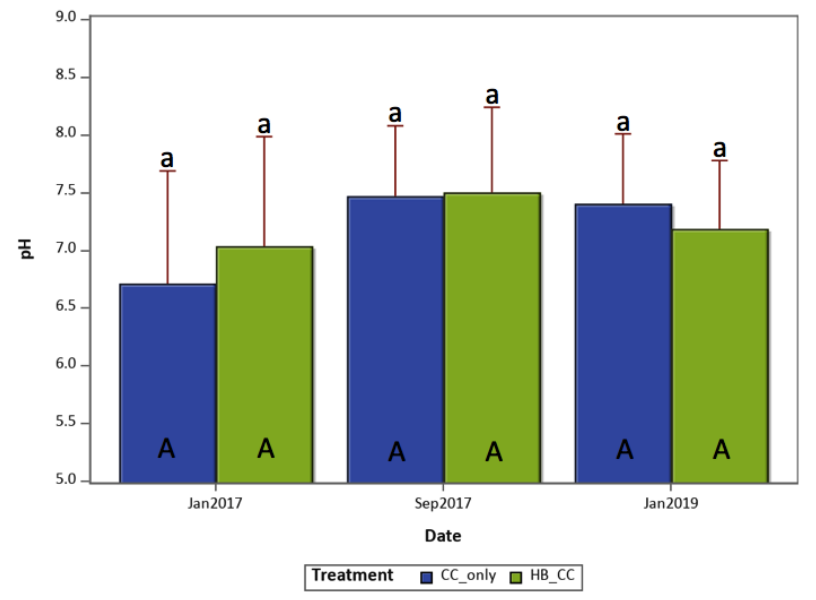

Figure 2. Changes in soil pH between CC-only and HB_CC at all sampling dates (mean and standard deviation) HB_CC $=$ Horse bedding application with cover cropping, CC-only = Cover cropping only. Means followed by different lower case letters within the same dates are significantly different $(\mathrm{p}<0.05)$. Means for the same treatment with different upper case letters for different sampling time are significantly different $(\mathrm{p}<0.05)$.

Bulk density of the soils ranged from 1.23 to $1.54 \mathrm{~g} \mathrm{~cm}^{-3}$ (Figure 3). Both HB_CC and CC-only practices showed a significant decrease in $\mathrm{BD}$ at the latter two sampling dates.

There was a significant difference in BD observed between HB_CC and CC-only practices at the second sampling dates (September 2017).

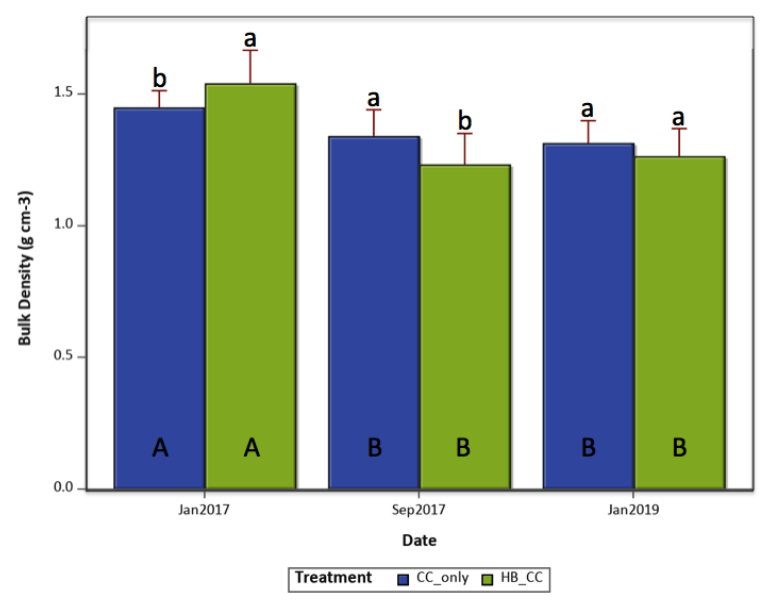

Figure 3. Changes in soil bulk density between CC-only and HB_CC at all sampling dates (mean and standard deviation)

HB_CC $=$ Horse bedding application with cover cropping, CC-only $=$ Cover cropping only. Means followed by different lower case letters within same date are significantly different $(p<0.05)$. Means for the same treatment with different upper case letters for different sampling date are significantly different $(\mathrm{p}<0.05)$.

Both $\mathrm{HB}$ _CC and CC-only practices showed a significant increase in MWHC at the latter two sampling dates (Figure 4). There was a significant difference in MWHC observed between HB_CC and CC-only practices at the third sampling date (January 2019). The MWHC of all soil samples after the two farming practices conducted was in range of $49.64 \%$ to $59.24 \%$. 


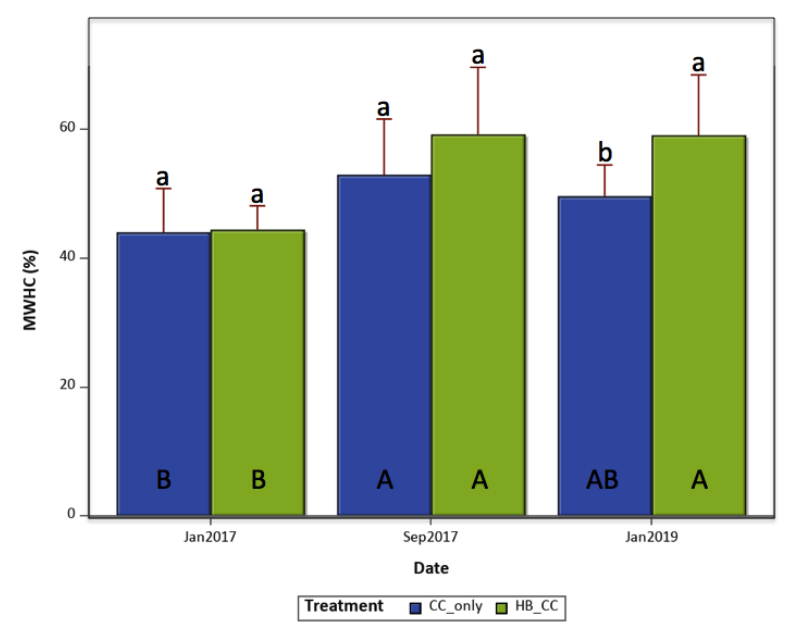

Figure 4. Changes in soil maximum water holding capacity between CC-only and HB_CC at all sampling dates (mean and standard deviation)

HB_CC $=$ Horse bedding application with cover cropping, CC-only = Cover cropping only. Means followed by different lower case letters within the same dates are significantly different $(\mathrm{p}<0.05)$. Means for the same treatment with different upper case letters for different sampling date are significantly different $(p<0.05)$.

The CEC of the soil samples collected at the third sampling date (January 2019) of both HB_CC and CC-only practices showed a significant increase compared to the former two sampling dates (Figure 5). However, a significant decrease in CEC was observed at the second sampling date (September 2019) compared to our baseline soil samples collect in January 2017. There was no significant difference in CEC observed between HB_CC and CC-only at all sampling dates. The CEC of the soil samples collected at January 2019 was approximately $4.5 \mathrm{cmolc} \mathrm{kg}^{-1}$ for both HB_CC and CC-only practices, while the CEC at January 2017 ranged from 2.09 to $2.36 \mathrm{cmolc} \mathrm{kg}^{-1}$ and the CEC at September 2017 ranged from 1.46 to $1.71 \mathrm{cmolc} \mathrm{kg}^{-1}$.

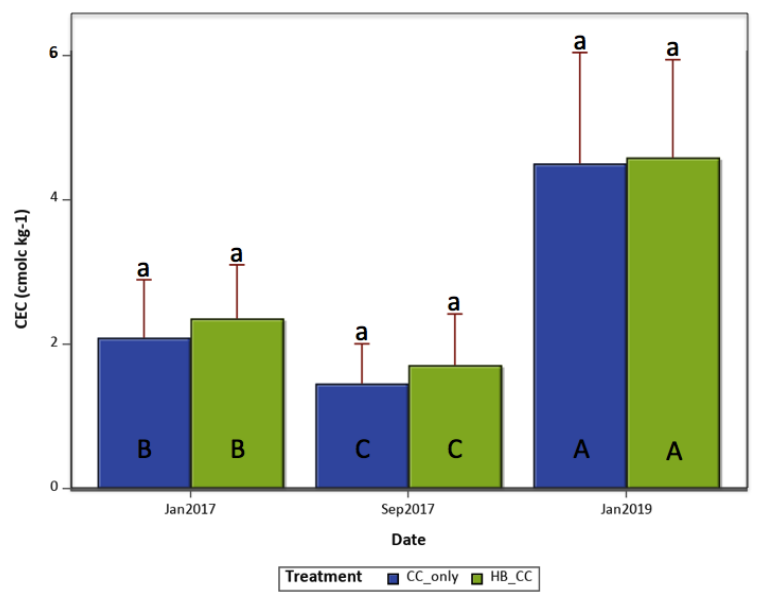

Figure 5. Changes in soil cation exchange capacity between CC-only and HB_CC at all sampling times (mean and standard deviation)

HB_CC $=$ Horse bedding application with cover cropping, CC-only = Cover cropping only. Means followed by different lower case letters within same time are significantly different $(p<0.05)$. Means for the same treatment with different upper case letters for different sampling time are significantly different $(\mathrm{p}<0.05)$.

Organic matter content of the soils ranged from 3.04 to $7.64 \%$ (Figure 6). There was a significant increase of approximately 4\% OM of soil samples collected at the second sampling date (September 2017) for HB_CC practice compared to the other two sampling dates. There was a significant difference in OM observed between HB_CC and CC-only practices at the second sampling date (September 2017), whereas no significant difference 
between the two practices at the other two sampling times. This increase in OM observed in the HB_CC treatment during September 2017 could be because the OM input to the soil from the newly terminated cover crop.

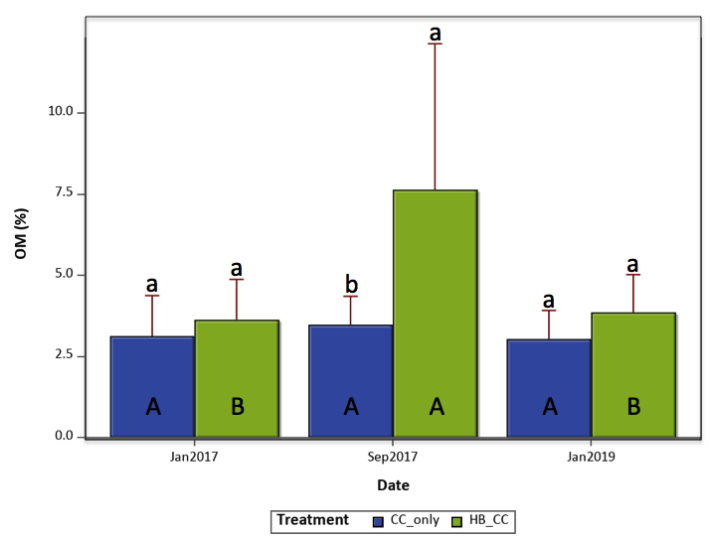

Figure 6. Changes in soil organic matter between CC-only and HB_CC at all sampling dates (mean and standard deviation)

HB_CC $=$ Horse bedding application with cover cropping, CC-only = Cover cropping only. Means followed by different lower case letters within same date are significantly different $(p<0.05)$. Means for the same treatment with different upper case letters for different sampling date are significantly different $(p<0.05)$.

Both HB_CC and CC-only practices showed a significant increase in Active $\mathrm{C}$ at the third sampling date (January 2019) compared to the former two sampling dates (Figure 7). A significantly higher amount of Active C in HB_CC than CC-only practice was observed in January 2019 as well.

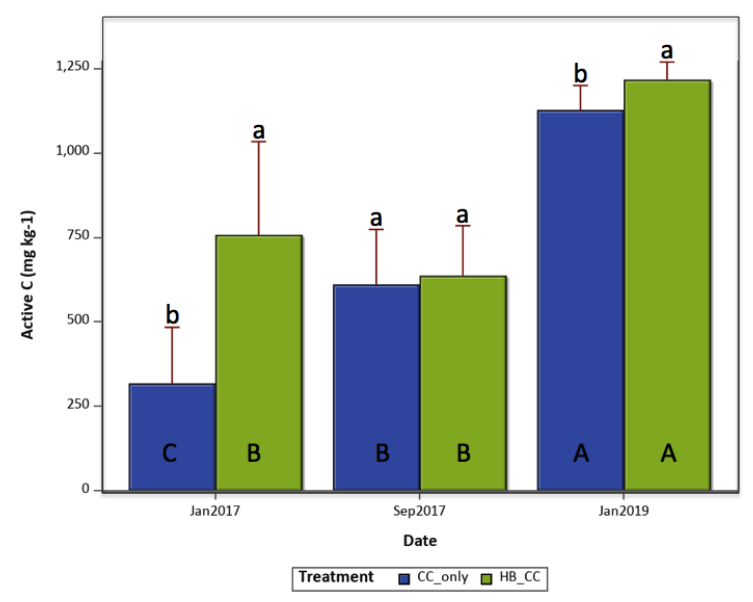

Figure 7. Changes in soil active carbon between CC-only and HB_CC at all sampling dates (mean and standard deviation)

HB_CC $=$ Horse bedding application with cover cropping, CC-only = Cover cropping only. Means followed by different lower case letters within same date are significantly different $(p<0.05)$. Means for the same treatment with different upper case letters for different sampling date are significantly different $(\mathrm{p}<0.05)$.

Soil protein of the soils ranged from 334.9 to $458.36 \mathrm{mg} \mathrm{kg}^{-1}$ (Figure 8). No significant changes were observed for both HB_CC and CC-only practices among all the sampling dates. At the second sampling date (September 2017), a significantly higher amount of soil protein was observed in HB_CC than in CC-only. 


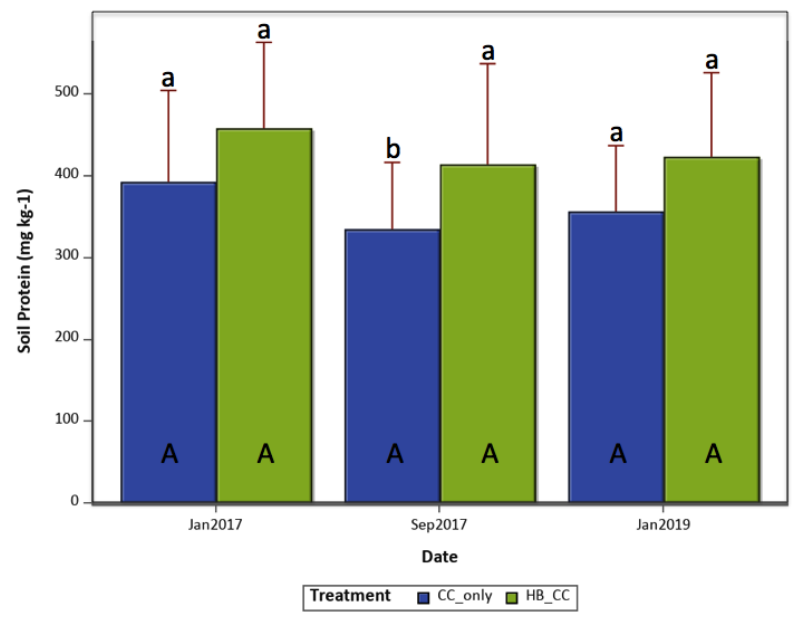

Figure 8. Changes in soil protein between CC-only and HB_CC at all sampling dates (mean and standard deviation)

HB_CC $=$ Horse bedding application with cover cropping, CC-only = Cover cropping only. Means followed by different lower case letters within same date are significantly different $(\mathrm{p}<0.05)$. Means for the same treatment with different upper case letters for different sampling date are significantly different $(\mathrm{p}<0.05)$.

In terms of nutrient contents, there were no significant changes in TKN for both HB_CC and CC-only practices among all the sampling times. No significant differences in TKN between HB_CC and CC-only were observed at all the sampling times as well. The range of TKN of all soil samples was from 1119 to $1614 \mathrm{mg} \mathrm{kg}^{-1}$ (Figure 9). Soil samples for both HB_CC and CC-only practices had a significant increase in Total P at the second sampling time (September 2017) compared to the other two sampling times. The soil samples collected at the latter two sampling times for both HB_CC and CC-only practices had significantly higher Mehlich $3 \mathrm{P}$ concentrations than our baseline soil samples collected at January 2017. The Mehlich $3 \mathrm{P}$ concentrations of soil samples for both HB_CC and CC-only practices ranged from 94.5 to $110.7 \mathrm{mg} \mathrm{kg}^{-1}$ after the two practices were conducted. There were no significant changes in Mehlich $3 \mathrm{~K}$ in soil samples for HB_CC among all the sampling times, while a significant change in Mehlich $3 \mathrm{~K}$ in soil samples for CC-only was observed at the third sampling time (January 2019) compare to the second time (September 2017). At the second sampling time (September 2017), a significant higher Mehlich 3 potassium concentration was observed in soil samples for HB_CC than for CC-only. 

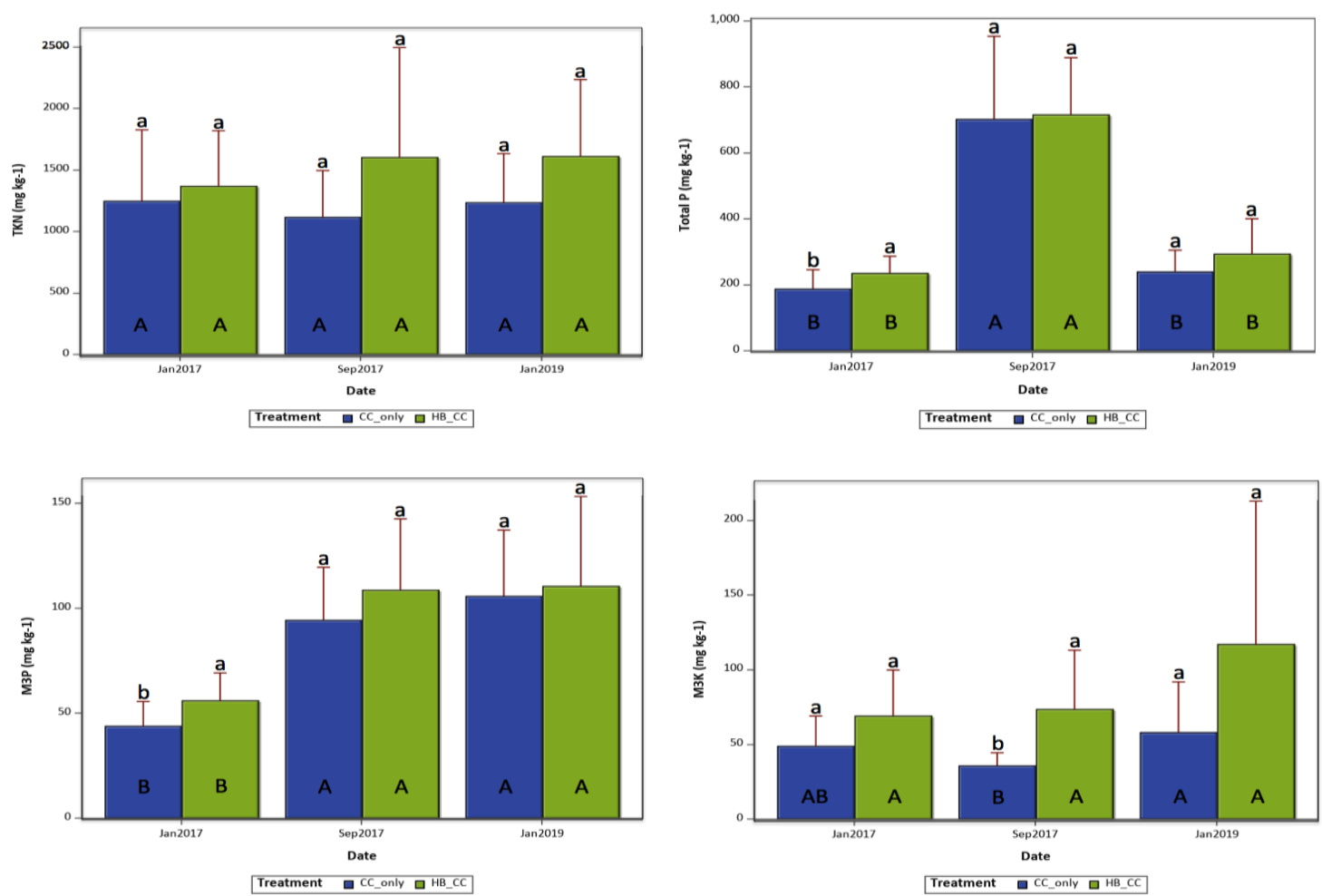

Figure 9. Changes in soil TKN, TP, Mehlich 3 P, and Mehlich 3 K concentrations between CC-only and HB_CC at all sampling dates (mean and standard deviation)

HB_CC $=$ Horse bedding application with cover cropping, CC-only = Cover cropping only. Means followed by different lower case letters within same date are significantly different $(p<0.05)$. Means for the same treatment with different upper case letters for different sampling time are significantly different $(\mathrm{p}<0.05)$.

\section{Discussion}

The $\mathrm{pH}$ of soils, which ranged from neutral to slightly alkaline, is a result of years of mixing with the underlying limestone (high calcium carbonate) bedrock in South Florida (Bhadha, Khatiwada, Galindo, Xu, \& Capasso, 2018). The large fraction of $\mathrm{Ca}$ and $\mathrm{Mg}$-based minerals within the limestone has the potential to raise $\mathrm{pH}$ in the topsoil. In our experimental trail the $\mathrm{pH}$ showed no statistically significant changes after horse bedding application and cover cropping practice since the $\mathrm{pH}$ of horse bedding material is slightly alkaline (7.37). Results indicate no obvious effects on $\mathrm{pH}$ due to the two regenerative farming practices (horse bedding application with cover cropping and cover cropping only). The significant decrease in bulk density (BD) at the two latter sampling dates (September 2017 and January 2019) for the two farming practices maybe due to the addition of OM from horse bedding materials and cover crops residues to the topsoil. The higher amounts of OM of horse bedding application with cover cropping practice (HB_CC) resulted in a significant lower BD than cover cropping practice only (CC-only) at the second sampling date (September 2017). It appears that HB_CC could do a better job than CC-only in lowering BD in a short period (few months). This lowering of soil bulk density is preferred since it's good for root growth, movement of air and water through soil, and alleviation of soil compaction. There was a significant increase in maximum water holding capacity (MWHC) after the two farming practices were applied. This increase in MWHC is probably due to the increase of OM content of the topsoil. Hudson (1994) reported that as OM content increased in sandy soils from $0.5 \%$ to $3 \%$, the available water holding capacity of the soil could be more than doubled. Bhadha et al. (2017) also demonstrated that growers could increase the MWHC of their soils by adopting farming practices that increase soil OM on mineral soils. HB_CC had a significantly higher MWHC than CC-only at the third sampling date (January 2019), which may be due to the higher amounts of organic matter remaining in the topsoil, which means HB_CC practice could have a long-term effect on MWHC than CC-only during our study period. Cation exchange capacity (CEC) significantly increased at the third sampling time (September 2017) for the two farming practices which maybe because of the addition of OM from horse bedding materials, cover crops and sugarcane residues left to the 
topsoil. Soil organic carbon content and clay-size particle fraction of soils are two primary factors to control CEC of soils (Parfitt, Giltrap, \& Whitton, 1995). The sandy soils inherently have a low organic carbon content in our study region $(<4 \%)$, hence the CEC values are low $\left(<3 \mathrm{cmolc} \mathrm{kg}^{-1}\right)$. Even in our experimental study after the CEC increased significantly, CEC values were still less than $5 \mathrm{cmolc} \mathrm{kg}{ }^{-1}$. However, this increase in soil CEC is considered as a positive change since high CEC helps to retain more essential nutrients for plant uptake, and keep non-foliar fertilizer and pesticides absorbed in the soil longer (Bhadha, Khatiwada, Galindo, Xu, \& Capasso, 2018). Interestingly, we observed a significant decrease in the CEC at the second sampling date (September 2017) after the two farming practice were applied. This decrease in soil CEC maybe because of the base cations being leached due to heavy precipitation. According to the data obtained from the Florida Automated Weather Network (FAWN), there was 12.90-inchs of rainfall in September 2017. Fang et al. (2017) demonstrated that the decrease in CEC was positively related to extreme precipitation since it led to base cations leaching. Increasing soil organic matter (SOM) content is the key to soil health improvements (Doran \& Zeiss, 2000). Organic matter improves soil structure, which reduces compaction, and minimizes erosion by binding soil particles into aggregates and increasing water infiltration into soils. Organic matter also serves as a reservoir of nutrients and water in the soil. Organic matter enhances soil microbial biodiversity and activity as well, which helps to reduce disease and pest damage to crops. Results indicated that HB_CC could be a beneficial practice to increase soil $\mathrm{OM}$ in a short period of time. Active C is considered a "leading indicator" of soil health (Schindelbeck, B.N. Moebius-Clune, D.J. Moebius-Clune, Kurtz, \& van Es, 2016), which is useful in early detection of changes in crop and soil management practices. It measures the fraction of soil OM that can be easily mineralized for soil microbial communities as available food and energy. A significant increase in Active $\mathrm{C}$ was observed after approximately 1.5-years for both HB_CC and CC-only practices.This indicated well decomposed organic matter maybe starting to build up. In addition, HB_CC did a better job in building up this active labile $\mathrm{C}$ pool than CC-only at the third sampling date (January 2019) since there was a significant higher amount of active C present in HB_CC treatment. Soil protein is an effective soil health indicator of bioavailable $\mathrm{N}$ that specifically indicates the quality of soil OM. It represents the large pool of organically bound $\mathrm{N}$ in soil OM, which measures the size of the pool being depolymerized, and serves as a reservoir of $\mathrm{N}$ that can be mineralized by soil microbial communities (Roberts \& Jones, 2008; Schindelbeck, B.N. Moebius-Clune, D.J. Moebius-Clune, Kurtz, \& van Es, 2016; Hurisso et al., 2018). Roper, Osmond, Heitman, Wagger, \& Reberg-Horton (2017) demonstrated that soil protein was positively related to corn grain yields $(\mathrm{r}=0.94)$. Results did not show any statistically significant changes in soil protein for both HB_CC and CC-only farming practices during our study period, which indicated this organic form of $\mathrm{N}$ may require a longer time to be detectable in soils. However, we observed a significant higher amount of soil protein in HB_CC than in CC-only at the second sampling date (September 2017), which indicated HB_CC could be more likely to increase the soil protein level in mineral soils.

Total Kjeldahl $\mathrm{N}$ quantifies the total organic nitrogen plus ammonia in soils. No statistically significant changes in TKN for both HB_CC and CC-only were observed among the three sampling times. It indicated these two farming practices may not have obvious effects on increasing TKN level in soils. However, this may be beneficial from an environmental point of view since no excessive $\mathrm{N}$ was applied on the soils. In terms of $\mathrm{P}$, we observed an increase in total $\mathrm{P}$ at the second sampling time (September 2017). From a soil health perspective, it was a great find because it indicated larger amounts of $\mathrm{P}$ would be available for subsequent crops. Mehlich-3 $\mathrm{P}$ is a good indicator of bioavailable $\mathrm{P}$ in mineral soils, and Mehlich-3 $\mathrm{P}$ showed significantly higher amounts of Mehlich-3 P after these two practices were applied. In terms of K, results indicated that HB_CC could do a better job than CC-only since there was a significant higher amount of Mehlich-3 K for HB_CC than for CC-only at the second sampling time (September 2017).

\section{Conclusions}

Based on the research results, both horse bedding application with cover cropping using Vigna unguiculata and the practice of cover cropping only in general had a positive effect on enhancing soil properties in mineral soils of South Florida. Especially, horse bedding application in combination with Vigna unguiculata had a more obvious effect on soil health. Both these practices did not show any significant effects on soil $\mathrm{pH}$, which was considered as a positive response since soils in South Florida are high in calcium carbonate with pH inherently higher than 7.2 already. Significant reduction in soil BD and increase in MWHC for both of these two practices are preferred from a soil health point of view since they are favorable conditions for plant growth. Horse bedding application with Vigna unguiculata had more obvious effects on soil BD in a short period and longer effects on MWHC. Significant increases in CEC observed in both of these practices suggest that the soils could have a greater ability to retain more essential nutrients, pesticides and insecticides within the topsoil. An increase in soil OM from horse bedding application with Vigna unguiculata in a short period of time is a beneficial practice 
from a soil health perspective. Active $\mathrm{C}$ results showed well decomposed organic matter started to build up after 1.5 years of these two farming practices being applied. The cover cropping only practice had limited influence on building up soil protein while horse bedding application with cover crops had a more obvious effect on increasing soil protein level over a short period of time. Nutritionally, the amounts of TKN stayed stable over the duration of the study period, which is beneficial from an environmental perspective since excessive amounts of $\mathrm{N}$ application would have otherwise contributed to surface and groundwater pollution. Both of these two practices have the potential to increase the $\mathrm{P}$ availability for subsequent crops.

In summary, horse bedding application with Vigna unguiculata may be a more effective practice since it showed more positive impacts on soil health parameters when compared to cover cropping alone. In addition, longer term field studies compared to fallow, environmental impacts especially from greenhouse gas emissions perspective, and economic analyses of horse bedding material and cover crops warrants investigation to gain a deeper understanding on the effects of these regenerative farming practices on improving soil quality of sandy soils. Results from this study will provide research-based information to local growers that will enable them to select appropriate regenerative farming practices that deliver the best results.

\section{Acknowledgements}

This project was funded by the Florida Rice Growers Inc., and USDA National Institute of Food and Agriculture. Hatch Project FLA ERC 005552. We would also like to thank Salvador Galindo and Dr. Raju Khatiwada with soil sampling and lab analyses.

\section{References}

Bhadha, J. H., Capasso, J. M., Khatiwada, R., Swanson, S., \& LaBorde, C. (2017). Raising soil organic matter content to improve water holding capacity, UF/IFAS Extension Publication, SL 447.

Bhadha, J. H., Khatiwada, R., Galindo, S., Xu, N., \& Capasso, J. M. (2018). Evidence of soil health benefits of flooded rice compared to fallow practice. Sustainable Agriculture Research, 7(4), 31-41. https://doi.org/10.5539/sar.v7n4p31

Doran, J. W., \& Zeiss, M. R. (2000). Soil health and sustainability: managing the biotic component of soil quality. Applied soil ecology, 15(1), 3-11. https://doi.org/10.1016/S0929-1393(00)00067-6

Fang, K., Kou, D., Wang, G., Chen, L., Ding, J., Li, F., \& Yang, Y. (2017). Decreased Soil Cation Exchange Capacity Across Northern China's Grasslands Over the Last Three Decades. Journal of Geophysical Research: Biogeosciences, 122(11), 3088-3097. https://doi.org/10.1002/2017JG003968

Hudson, B. D. (1994). Soil organic matter and available water capacity. Journal of Soil and Water Conservation, 49(2), 189-194.

Hurisso, T. T., Moebius-Clune, D. J., Culman, S. W., Moebius-Clune, B. N., Thies, J. E., \& van Es, H. M. (2018). Soil protein as a rapid soil health indicator of potentially available organic nitrogen. Agricultural \& Environmental Letters, 3, 180006. https://doi.org/10.2134/ael2018.02.0006er

Jenkinson, D. S., \& Powlson, D. S. (1976). The effects of biocidal treatments on metabolism in soil-V: A method for measuring soil biomass. Soil Biology and Biochemistry, 8(3), 209-213. https://doi.org/10.1016/0038-0717(76)90005-5

Nick, J. (2019). Regenerative agriculture: how it works on the ground. Circulate News. Retrieved from https://medium.com/circulatenews/regenerative-agriculture-how-to-grow-food-for-a-healthy-planet-9a5f637 c0f3e

Parfitt, R. L., Giltrap, D. J., \& Whitton, J. S. (1995). Contribution of organic matter and clay minerals to the cation exchange capacity of soils. Communications in Soil Science and Plant Analysis, 26(9-10), 1343-1355. https://doi.org/10.1080/00103629509369376

Paul, S. (2013). Regenerative Agriculture A Soil Health Focus. A report for Nuffield Australia Farming Scholars. Retrieved from https://nuffieldinternational.org/live/Report/AU/2013/paul-serle

Pretty, J. N. (1995). Regenerating agriculture: policies and practice for sustainability and self-reliance. Joseph Henry Press.

Roberts, P., \& Jones, D. L. (2008). Critical evaluation of methods for determining total protein in soil solution. Soil Biology and Biochemistry, 40(6), 1485-1495. https://doi.org/10.1016/j.soilbio.2008.01.001

Rodale Institute. (2014). Regenerative Organic Agriculture and Climate Change A Down-to-Earth Solution to Global Warming. Retrieved from https://rodaleinstitute.org/wp-content/uploads/rodale-white-paper.pdf 
Roper, W. R., Osmond, D. L., Heitman, J. L., Wagger, M. G., \& Reberg-Horton, S. C. (2017). Soil health indicators do not differentiate among agronomic management systems in North Carolina soils. Soil Science Society of America Journal, 81(4), 828-843. https://doi.org/10.2136/sssaj2016.12.0400

Schindelbeck, R. R., Moebius-Clune, B. N., Moebius-Clune, D. J., Kurtz, K. S., \& van Es, H. M. (2016). Cornell University comprehensive assessment of soil health laboratory standard operating procedures. Cornell Univ., Ithaca, NY.

Sherwood, S., \& Uphoff, N. (2000). Soil health: research, practice and policy for a more regenerative agriculture. Applied Soil Ecology, 15(1), 85-97. https://doi.org/10.1016/S0929-1393(00)00074-3

Sumner, M. E., \& Miller M. P. (1996). Cation exchange capacity and exchange coefficient. In Sparks (ed) Methods of soil analysis (pp. 1201-1230). part 3: Chemical Methods., Madison, Wisconsin.

\section{Copyrights}

Copyright for this article is retained by the author(s), with first publication rights granted to the journal.

This is an open-access article distributed under the terms and conditions of the Creative Commons Attribution license (http://creativecommons.org/licenses/by/3.0/). 